\title{
A Articulação "Themata-Fundos Tópicos": por uma Análise Pragmática da Linguagem
}

\author{
Laura Camara Lima ${ }^{1}$ \\ Universidade Federal do Mato Grosso \\ Centre Edgar Morin - EHESS - Paris CNRS
}

\begin{abstract}
RESUMO - Este trabalho defende a articulação themata-fundos tópicos, visando uma abordagem pragmática da linguagem. $\mathrm{O}$ método Alceste permite operar essa articulação. As classes que ele detecta correspondem às tomadas de posição dos enunciadores. Os fundos tópicos contém themata. As extremidades dos eixos fatoriais correspondem às taxinomias, às polaridades opostas que dinamizam as relações intergrupos. Esta abordagem pragmática da linguagem, por intermédio do programa Alceste, fornece ao psicólogo social os elementos necessários para a construção de um sistema explicativo, capaz de restituir o elo perdido entre as distribuições dos mundos lexicais e as relações intergrupos.
\end{abstract}

Palavras-chave: themata; fundos tópicos; pragmática; representação social; alceste.

\section{Articulating the Concepts of "Themata" and of "Topic Ground": Toward a Pragmatic Approach of Language}

\begin{abstract}
This article stands up for relationships among the concepts of Themata and of Topic ground, in order to develop a pragmatic approach to language. The Alceste method is an effective tool to operate this articulation. The clusters distribution that it detects reproduces the positions taken by different groups of speakers. The Topic ground contains Themata. The lexical oppositions, which the factorial analysis makes visible, correspond to the dichotomies, the polarities that keep in motion the inter-group relations. This pragmatic approach to language, through Alceste, provides all the information that the social psychologist needs to conceive one model capable to rescue the link between lexical worlds and inter-group relations.
\end{abstract}

Key words: themata; topic ground; pragmatics; social representation; alceste.

A abordagem pragmática da linguagem é um instrumento indispensável ao psicólogo social que se interessa em estudar as relações intergrupos, a troca de informações e de conhecimentos, e a produção de discurso e de representações sociais. Afim de operá-la, este trabalho preconiza a articulação entre o conceito de "themata", tal como ele foi definido por Holton (1981, 1982), desenvolvido por Moscovici e Vignaux (1994) e Marková (2000, 2003), e o conceito de "fundos tópicos", tal como definido e desenvolvido por Reinert (1990, 1993, 1999, 2001).

Esta articulação "themata - fundos tópicos" é legítima, pois ambos conceitos são ligados a paradigmas similares à estrutura ternária. Ela é duplamente pertinente, pois inaugura possibilidades até então pouco exploradas em psicologia social: primeiro, porque ela torna operacional o uso empírico do conceito de themata; e segundo, porque ela contribui para o desenvolvimento teórico do conceito de fundos tópicos. A abordagem pragmática da linguagem que essa articulação opera é extremamente útil, porque permite compreender como a dinâmica intergrupo atualiza os themata e como os themata reativam a dinâmica intergrupo e reanimam a comunicação relativa ao objeto.

\section{Três modelos teóricos fundados sobre paradigmas similares} à estrutura ternária

Os três modelos teóricos tratados aqui são fundados sobre um mesmo paradigma ternário. $\mathrm{O}$ primeiro diz respeito à

1 Endereço: R. Iperoig, nno 864 ap. 123. CEP: 05016-000. São Paulo. SP. E-mail: camaralima.laura@gmail.com filosofia da ciência desenvolvida por Gerald Holton (1981, 1982), tendo como objeto a imaginação e a invenção científicas. O segundo diz respeito à Teoria das Representações Sociais, como ela foi definida por Serge Moscovici (1961, 1984) e Denise Jodelet (1989a, 1989b), tendo como objeto a produção de conhecimentos de senso comum. E o terceiro diz respeito à perspectiva "Pragmatista"2 proposta por Max Reinert (1990, 1993, 1999, 2001), cujo objeto são os mundos lexicais ou os fundos tópicos detectados pelo programa Alceste. Ora, esses três modelos têm em comum o fato de ser construídos sobre uma base ternária, mesmo se cada qual guarda a sua especificidade, de acordo com o seu domínio de investigação. Nos três casos, os autores introduzem um novo elemento quando concebem as relações sujeito - objeto. A introdução desse terceiro elemento aumenta o dinamismo das inter-relações e completa o modelo.

Nos seus estudos sobre a formação dos conceitos e teorias científicos, Holton (1981) constata a insuficiência explicativa do plano "contingente" formado pelos eixos empírico e analítico, e defende a necessidade de introduzir um terceiro eixo, perpendicular aos dois outros. Esse terceiro eixo dá acesso à dimensão que Holton (1981) batiza de "temática", onde se encontra o "nosso arsenal de instrumentos imaginativos". Ele introduz assim um modelo epistemológico mais aperfeiçoado e mais abrangente de investigação da história da ciência.

2 O termo original em francês é " pragmatiste ". Toda tradução de termos em francês foi realizada pelo autor do texto. 
Nos seus estudos sobre os fenômenos de comunicação e ideologia, Moscovici (1984) concebe o "olhar psico-social" como "uma relação de três termos: Sujeito individual - Sujeito social - Objeto. [...]. O que pressupõe uma mediação constante, uma "terceiridade" segundo a expressão do filósofo americano Peirce" (p. 9). A introdução do sujeito social como terceiro elemento permite a Moscovici superar a concepção bipolar herdada da filosofia clássica e fundar uma nova corrente em psicologia social que ele batizou de "Teoria das Representações Sociais".

Quando elabora as suas próprias teorizações, Reinert (2003) se inspira em Peirce, que dizia: "um representamem é o sujeito de uma relação ternária, com um segundo chamado objeto, em relação a um terceiro chamado interpretante" (p. 399, tradução minha). Ele considera (também como Peirce) que o objeto constrói o sujeito da mesma maneira que o sujeito constrói o objeto. Segundo Reinert (1999), sujeito e objeto são tão imbricados um no outro que é mais sensato tratá-los conjuntamente do que tentar isolá-los artificialmente.

A abordagem pragmática da linguagem evocada neste trabalho foi concebida em consonância com os paradigmas ternários citados. A operacionalização da articulação "themata-fundos tópicos" permite justamente estudar os aspectos dinâmicos, que até então permaneciam pouco acessíveis aos psicólogos sociais que procuram reconstituir os vínculos entre a análise da linguagem e a produção de conhecimentos, a formação das representações sociais, a comunicação entre grupos.

\section{"Thema" e "themata" nas origens da imaginação e da invenção científicas}

O conceito de thema foi inicialmente utilizado por Holton. Suas pesquisas empíricas levaram-no a postular a existência do que ele batizou de "thema" ou "themata" e que ele definiu como "concepções primeiras" às quais os homens de ciência aderem, que modulam a maneira pela qual a imaginação deles é governada. Trata-se de concepções fundamentais, estáveis, largamente difundidas, comuns a um grande número de cientistas; que se concretizam em conceitos, métodos ou hipóteses, que orientam a atividade de pesquisa e que não podem ser reduzidas nem à observação, nem ao cálculo.

Tendo estudado a evolução histórica das invenções científicas, Holton (1982) observa que: a) o número de themata é restrito e quase invariável ao longo dos anos; b) de vez em quando acontece de um deles perder todo crédito como sistema explicativo, em um determinado momento da história; e c) raramente acontece de um deles desaparecer para sempre. Holton (1982) nota que os themata, em sua maioria, "[...] prosperam, declinam e desenvolvem-se de novo, segundo as vagas das necessidades do momento ou das modas intelectuais" (p. 59, tradução minha). Suas pesquisas conduziram-no a descobrir que as teorias científicas evoluem graças a um movimento dialético de thema opostos. Esses thema opostos são facilmente detectáveis por intermédio do que Holton chama de "díades antitéticas", às quais ele faz referência pelos seguintes exemplos: "simplicidade - complexidade"; "reducionismo - holismo"; "continuidade - descontinuidade"; "análise - síntese"; "permanência-mudança"; "invariância - evolução"; "hierarquia-unidade".

\section{"Thema" e "themata" nas origens das representações sociais}

Vinte anos mais tarde, Moscovici e Vignaux (1994) retomam o conceito de themata, caído no esquecimento entretempo, afim de adaptá-lo ao quadro da psicologia social e de utilizá-lo relativamente: à organização do pensamento social, à partilha de conhecimentos do senso comum e à formação das representações sociais. O conceito se transformará nessa passagem da filosofia da ciência à psicologia social. Enquanto Holton $(1981,1982)$ se referia ao "plano temático", Moscovici e Vignaux (1994) se referem ao "plano axiomático". Enquanto o filósofo da ciência se referia às "predisposições comuns" presentes num grande número de teorias científicas e às "concepções primeiras", aos "princípios fundamentais", aos "estilos de pensamento" que intervém na composição da imaginação científica, os psicólogos sociais se referem aos "conceitos", aos "princípios primeiros", agindo ao nível do pensamento social e às "noções primeiras", às "idéias-força" ou às "imagens" que intervém na formação das representações sociais.

A noção de "thema"3 revisitada por Moscovici e Vignaux (1994) designa o que eles chamam de "quadros de pensamento pré-existentes", tributários de sistemas de crenças, ancorados em valores, tradições, imagens do mundo e do ser, nos quais as representações sociais se inscrevem. Esses autores assumem, como Holton (1982), que os themata estão submetidos a um movimento dinâmico, gerado pela alternância de pólos opostos. A integração de cada thema perceptível se funda em uma ou em várias noções, ancorando sistemas de oposições. Cada representação é formada a partir de um esquema funcional fundado sobre antinomias, entretidas pela relação dialética de oscilação entre tensão - integração de teses opostas.

Seis anos mais tarde, a psicóloga social Ivana Marková (2000) chegará a uma conclusão semelhante. Nas suas pesquisas sobre as representações sociais, ela pode constatar a existência de "themata de base", implícitos na cultura e profundamente enraizados nos indivíduos e no pensamento social. Ela observa que a percepção, o pensamento, o saber e a linguagem são de natureza oposicional; o que significa que eles são fundados a partir de taxinomias; como, por exemplo: "moral/imoral", "liberdade/opressão", "simétrico/assimétrico". Uma vez que estas taxinomias são explicitamente formuladas no pensamento social, elas adquirem significações diferentes segundo os diferentes grupos ou classes de indivíduos. Quando ativas, elas se comportam como themata, transformando-se em objeto de desejo, de temores, de ambições e de projeção identitária, tornando-se capazes de gerar representações sociais.

Ora, é este caráter dinâmico do conceito de themata, tal como ele é definido nesses dois modelos, que autoriza o paralelo com o conceito de fundos tópicos, tal como ele é demarcado na semiologia de Max Reinert.

3 O termo original nos textos de Moscovici e Vignaux é thème. Mas para que fique claro que os autores não estão se referindo aos temas de uma análise de conteúdos temática, mas sim aos temas enquanto quadros de pensamento e noções ancorando sistemas de oposições, o uso do termo thema foi padronizado em todo o texto, de maneira a facilitar o entendimento. A discussão sobre as sutilezas terminológicas será feita em trabalhos específicos para este fim. 


\section{Mundos lexicais e fundos tópicos nas origens dos lugares comuns ou pontos de vista coletivos}

Para construir a sua própria semiologia, Reinert (2001) inspira-se na concepção de Charles Sanders Peirce, que ele qualifica de "fundamentalmente dinâmica". O seu objetivo é o de estudar o sentido no seu dinamismo complexo, dando conta, ao mesmo tempo, das formas nas quais ele se fixou e das transformações pelas quais ele passou. Reinert considera que toda investigação relativa ao sentido de um discurso ou de um texto deve inevitavelmente considerar as seguintes limitações: a) o sentido original é inacessível, do mesmo modo que o sentido transmitido pelo signo é intangível; e, b) sujeito e objeto são imbricados numa construção mútua, em continua evolução. Tendo constatado esta extrema instabilidade do sentido (condenado a se reconstruir a cada atualização, a cada tradução de um signo ao outro, a cada troca entre enunciadores) Reinert compreende que ele só pode ser atingido por intermédio das "pegadas de passo" que ele deixa pelo caminho.

Ciente dessas limitações, Reinert (2001) decide utilizar a noção de sujeito enunciador (ao invés da noção de indivíduo) e privilegiar a modelização do discurso do tipo enunciado - fundamento (ao invés da modelização do tipo sujeito - predicado). O sujeito enunciador está sempre ligado a um "lugar", que não existe em si mesmo, independentemente dele. Cada "lugar" é identificável ao mesmo tempo pela sua coerência interna, quanto pela sua oposição a outros lugares. Trata-se de um lugar habitado por um sujeito, que funciona como um espaço de atração para a atividade deste sujeito. No caso em que o sujeito é coletivo, estes lugares se transformam em lugares comuns e se impõem ao enunciador, mais do que são escolhidos por ele. Reinert utiliza a noção de enunciado porque ela designa um ato, que reúne, num mesmo traço lingüístico, o objeto designado e o sujeito que o designa. Essa noção compreende um ponto de vista particular e implica a existência de um sujeito, numa certa modalidade do fazer ou do ser. Para esse autor, o enunciado é uma verdadeira encenação, na qual três elementos coexistem: mundo lexical, sujeito enunciador e lógica local.

Reinert identifica os fundos tópicos como sendo os diferentes momentos da atividade do sujeito enunciador e os diferentes pontos de vista que se superpõem num mesmo lugar, e que ele explica como sendo espaços intermediários, mediando a ação. Como os contornos e os limites desses fundos tópicos são imprecisos, Reinert decide identificá-los pelo contraste ou conflito e conclui pela necessidade de dar a eles uma definição operacional; o que o conduz a formular o seu próprio método de análise estatística de dados textuais em ciências humanas.

Esse método se concretiza em um programa informático que ele batiza de Alceste. Reinert concebe um procedimento no qual a detecção e o exame estatístico das distribuições das formas lexicais presentes no texto contribui para circunscrever os lugares da enunciação onde Sujeitos e Mundo se elaboram, a partir de lugares primeiros, insistentes, repetitivos, que ele nomeia fundos tópicos. Por intermédio das oposições lexicais que ele detecta, Alceste consegue atingir as oposições entre os diferentes pontos de vista coletivos inscritos no vocabulário de um texto. O objetivo do programa Alceste é de estabelecer uma cartografia dos principais lugares comuns, sobre os quais se arquitetam, simultaneamente, o mundo do discurso e o mundo dos enunciadores.

\section{A equivalência entre os themata e os fundos tópicos}

Os conceitos de themata e de fundo tópico possuem, ambos, as seguintes características: a) eles dizem respeito a topoï, a forte intensidade energética; b) trata-se de lugares de forte atratividade lexical (isto quer dizer: lugares que atraem os lexemas na direção deles, alinhando-os em relação a um determinado eixo) e de forte produção semântica (isto quer dizer: lugares de produção de sentido); e c) trata-se de posicionamentos relativos que possuem características tópicas, analógicas mais do que de qualidades espaciais ou digitais. $\mathrm{O}$ fato de que ambos os conceitos possuam todos esses atributos em comum contribui amplamente para a validação da articulação proposta neste trabalho.

A abordagem pragmática da linguagem, baseada no agenciamento operacional dos conceitos de themata e de fundos tópicos se revela particularmente adequada ao pesquisador em psicologia social, o qual precisa dar conta de um triplo objetivo, no sentido de: a) obter informações a respeito dos elementos que dinamizam as relações intergrupos; b) levantar como essas relações (freqüentemente assimétricas) determinam o uso do léxico e o fluxo da comunicação; e c) identificar os themata que animam a construção das representações contidas nesses mundos lexicais.

A constatação da equivalência entre os fundos tópicos (presentes ao nível da linguagem) e os themata (presentes ao nível do imaginário coletivo) autoriza o psicólogo social a praticar uma análise pragmática do texto ou do discurso, de maneira a estudar a topologia dos fundos tópicos, com $\mathrm{o}$ intuito de atingir os themata em ação na linguagem e de abarcar os aspectos dinâmicos das relações intergrupos que mobilizaram as tomadas de posição enunciativas.

\section{A equivalência entre as polaridades antitéticas do vocabulário e as posições antagonistas dos protagonistas}

Holton (1981) demonstrou que as célebres controvérsias entre grandes cientistas dizem sempre respeito a antinomias primordiais, nas quais cada protagonista representa uma facção, uma posição diferente. Elas remetem, freqüentemente, a pares (por vezes trios) de thema antitéticos.

Moscovici e Vignaux (1994) postulam que toda representação social corresponde à expressão, reiterada no discurso, das trocas de teses entre grupos ou categorias de indivíduos de interesses opostos, nas quais eles negociam themata. Esses diferentes grupos ou categorias de indivíduos estão mobilizados em torno de um objeto investido, cujo desejo (a cobiça, a necessidade) nutre a dinâmica intergrupos e garante a manutenção da comunicação. Ambas as facções estão ligadas ao mesmo objeto, mas para cada uma delas ele se apresenta de uma maneira diversa e representa algo diferente.

Essa interação dos grupos mobilizados em torno de um dado objeto, num dado período, deixa os seus rastros na linguagem. Moscovici e Vignaux (1994) preconizam um exame atento dos traços lingüísticos contidos no que eles chamam de "pacotes de discurso", com o objetivo de identificar o que os motiva tais traços e o que eles inauguram num momento histórico dado, numa situação dada, em respeito a um dado objeto. Eles afirmam a necessidade de extrair da massa considerável de traços lingüísticos o que chamam de "legendas de leitura que se impõem ao leitor ou ao ouvinte" (Moscovici \& Vignaux, 1994, p. 62). 
Tendo me interessado por esse problema, procurei: a) o instrumento viável à identificação e à análise dessas formações lexicais; e b) a metodologia que tornasse possível delimitar pacotes de discurso, examinar os indícios lexicais que eles contém e transformá-los em indicadores por meio dos quais fosse possível praticar uma análise de linguagem que respondesse aos interesses da psicologia social. Ora, eu logo me dei conta que o método Alceste responde perfeitamente a todos esses critérios; o que faz dele o instrumento ideal para o desenvolvimento de um tal projeto. Sua originalidade vem do fato que ele opera uma análise estatística de dados textuais que é capaz de captar as etapas transitórias, em que as diferentes representações estão em conflito e o sujeito deve se multiplicar para dominá-las. Reinert (2001) resume assim: "Não é tanto quem fala ou o que se diz que nos interessa, mas de onde se fala a cada instante!" (p. 34).

Graças à sua competência pragmática, Alceste é um instrumento particularmente adequado aos objetivos do psicólogo social. Os fundos tópicos que ele detecta se revelam bastante úteis. Eles servem de referência por intermédio da qual o psicólogo social consegue captar o conjunto das tomadas de posição antagônicas, as quais se constroem umas em relação às outras. Em síntese, a abordagem pragmática da linguagem por meio do programa Alceste ajuda o pesquisador a encontrar na forma singular das respostas uma imagem das relações intergrupos.

\section{A isotopia entre a distribuição das classes e as tomadas de posição dos protagonistas}

Um pesquisador em psicologia social está sobretudo interessado em encontrar o elo perdido que liga os mundos lexicais extraídos do discurso e as dinâmicas intergrupos das quais o discurso se originou. Desse ponto de vista, o método Alceste se mostra vantajoso. O interesse principal é o de detectar a existência de uma isotopia entre os resultados que o programa Alceste produz e as posições de enunciação tomadas pelos diferentes grupos de sujeitos. As classes servem de marcadores de themata. As extremidades de cada eixo fatorial correspondem às taxinomias opostas, as quais alimentam as relações intergrupos. Os planos fatoriais correspondem às reproduções bidimensionais das tensões entre os múltiplos fatores. As representações gráficas que se encontram no relatório final fornecido pelo programa oferecem uma visão de conjunto dessas taxinomias antinômicas.

\section{Conclusão}

Em síntese, a abordagem pragmática da linguagem pelo método Alceste permite captar os grupamentos e as classificações lexicais a serem colocados em relação com os indicadores psicossociais, de modo a elucidar a maneira pela qual as diferentes populações implicadas nas relações intergrupos relativas a um objeto social dado tomam posição umas em relação às outras e cada qual em relação ao objeto.

Essa abordagem fornece ao pesquisador: a) os meios de estudar, de uma maneira integrada, a comunicação intergrupos, a partilha de conhecimentos e a produção de representações sociais; b) as chaves necessárias ao estabelecimento das correspondências e das transposições entre o nível lexical e o nível representacional; e c) os elementos para construir um único sistema explicativo, capaz de dar conta das trocas simbólicas e da dinâmica da relação.

\section{Referências}

Holton, G. (1981). L'imagination scientifique. Paris: Gallimard. Holton, G. (1982). L'invention scientifique: Themata et interprétation. Paris: PUF.

Jodelet, D. (Org.) (1989a). Les représentations sociales. Paris: PUF.

Jodelet, D. (Org.) (1989b). Folies et représentations sociales. Paris: PUF.

Marková, I. (2000). Des Themata de base des représentations sociales du SIDA. Em C. Garnier (Org.), Les formes de la pensée sociale (pp. 55-77). Paris: PUF.

Marková, I. (2003). Dialogical triads and three-component processes. Em Dialogicality and Social representations, the dynamics of Mind (pp. 147-176). Cambridge: Cambridge University Press.

Moscovici, S. (1961). La psychanalyse son image son public (2 ${ }^{\mathrm{a}} \mathrm{ed}$.). Paris: PUF.

Moscovici, S. (Org.) (1984). Psychologie sociale. Paris: PUF.

Moscovici, S., \& Vignaux, G. (1994). Le concept de Themata. Em C. Guimelli(Org.), Structures et transformations des représentations sociales (pp. 25-72). Neuchâtel: Delachaux et Niestlé.

Reinert, M. (1990). Alceste, une méthodologie d'analyse des données textuelles et une application: Aurélia de Gérard de Nerval. Bulletin de Méthodologie Sociologique, 26, 24-54.

Reinert, M. (1993). Les "mondes lexicaux" et leur "logique" à travers l'analyse statistique d'un corpus de récits de cauchemars. Langage \& Société, 66, 5-39.

Renert, M. (1999). Quelques interrogations à propos de 1'“objet" d'une analyse de discours de type statistique et de la réponse “Alceste". Langage \& Société, décembre, no 90, 57-70.

Reinert, M. (2001). Alceste, une méthode statistique et sémiotique d'analyse de discours. Application aux "Rêveries du promeneur solitaire". La Revue Française de Psychiatrie et de Psychologie Médicale, V(49), 32-37.

Reinert, M. (2003). Le rôle de la répétition dans la représentation du sens et son approche statistique par la méthode "ALCESTE". Sémiotica, 147(1/4), 389-420.

\author{
Recebido em 30.06.2007 \\ Primeira decisão editorial em 29.01.2008 \\ Versão final em 31.01.2008 \\ Aceito em 10.03.2008
}

